\title{
Deconstruction of Woody Biomass via Protic and Aprotic Ionic Liquid Pretreatment for Ethanol Production
}

Lalitendu Das ${ }^{1,2 \#}$, Ezinne C. Achinivu ${ }^{1,2 \#, ~ C a r o l i n a ~ A r a u j o ~ B a r c e l o s ~}{ }^{3,4}$, Eric Sundstrom ${ }^{3,4}$, Bashar Amer $^{1,3}$, Edward E. K. Baidoo ${ }^{1,3}$, Blake A. Simmons ${ }^{1,3}$, Ning Sun ${ }^{3,4}$, John M. Gladden ${ }^{1,2^{*}}$

${ }^{1}$ Joint BioEnergy Institute, 5885 Hollis Street, Emeryville, California 94608, United States

${ }^{2}$ Deparment of Biomass Science and Conversion Technology, Sandia National Laboratories, 7011 East Avenue, Livermore, California 94551, United States

${ }^{3}$ Biological Systems and Engineering Division, Lawrence Berkeley National Laboratory, 1 Cyclotron Road, Berkeley, California 94720, United States

${ }^{4}$ Advanced Biofuels Process Development Unit, Lawrence Berkeley National Laboratory, 5885 Hollis Street, Emeryville, California 94608, United States \#These authors contributed equally

${ }^{*}$ Corresponding to: Dr. John M. Gladden, Joint BioEnergy Institute Email: jmgladden@lbl.gov

\section{Pages: 7}

Figures: 6 


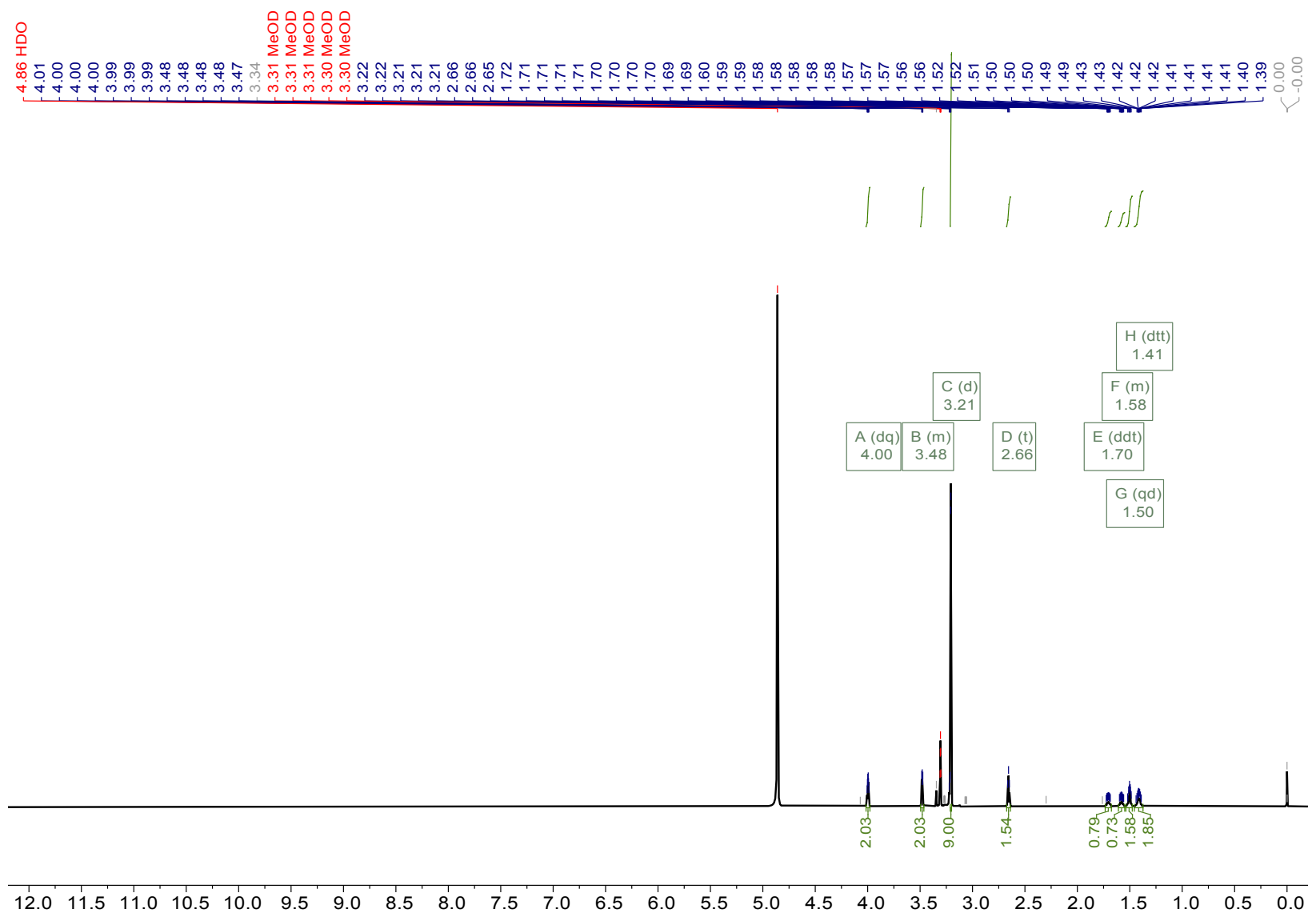

Figure S1. 1H-NMR spectra of [Ch][Lys] with MeOD as an external solvent 


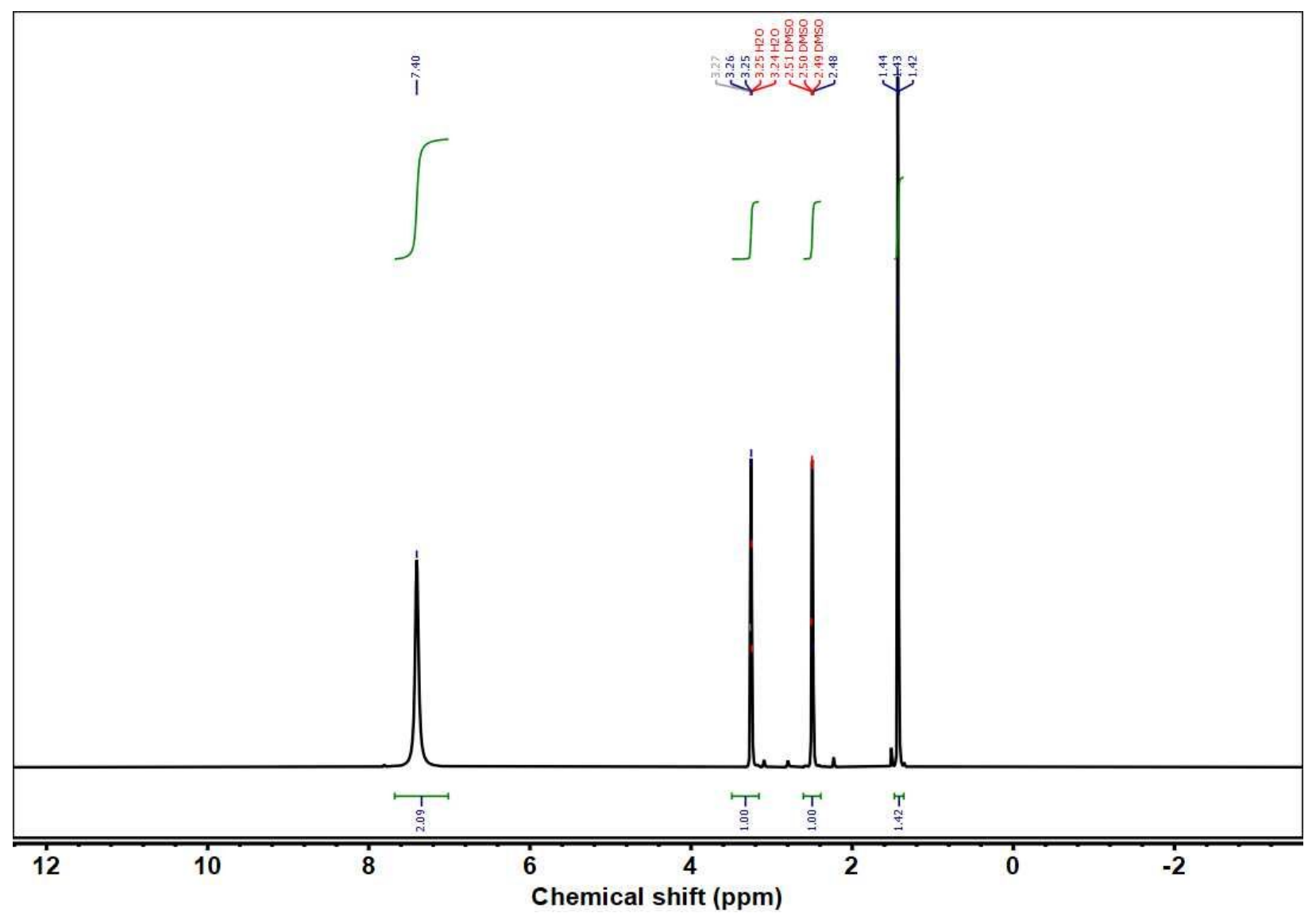

Figure S2. 1H-NMR spectra of [EOA][OAc] with DMSO-D6 as an external solvent 
(A)

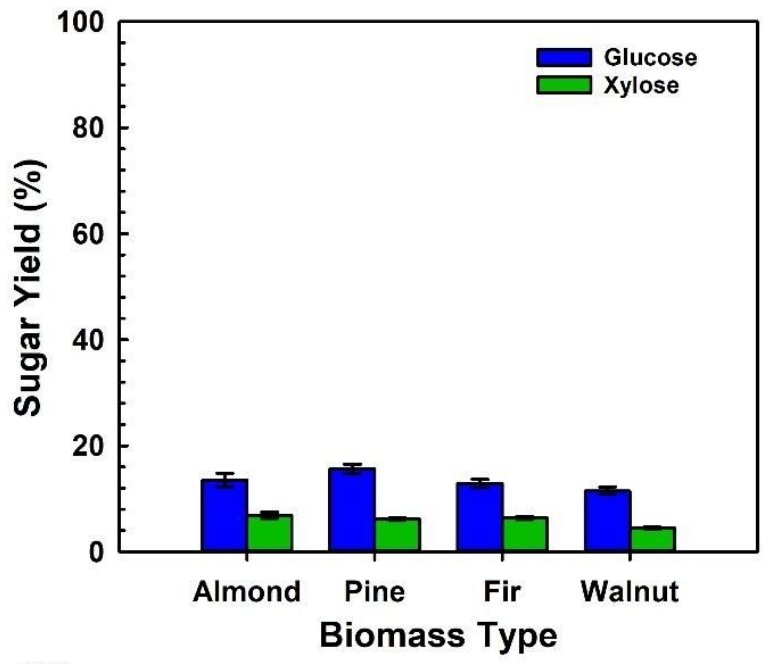

(C)

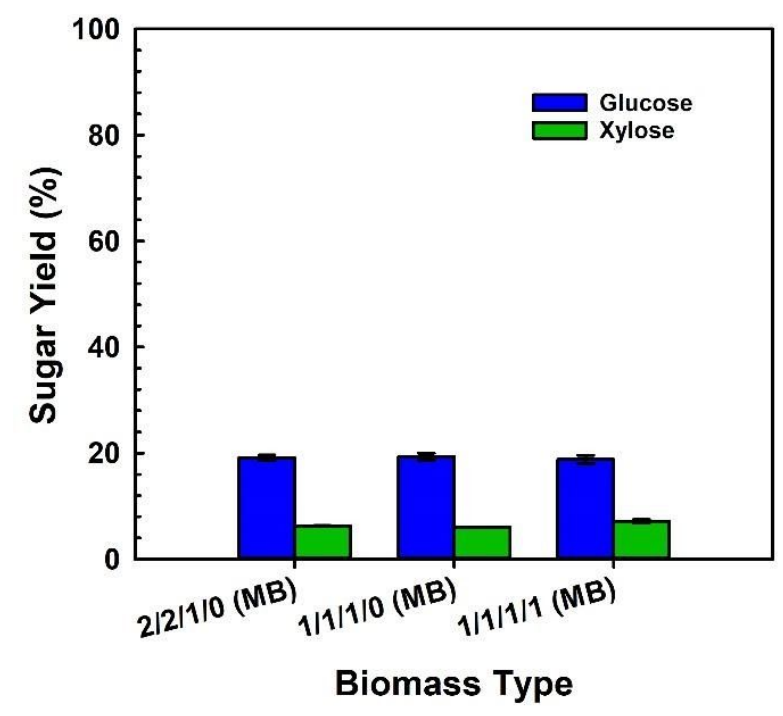

(B)

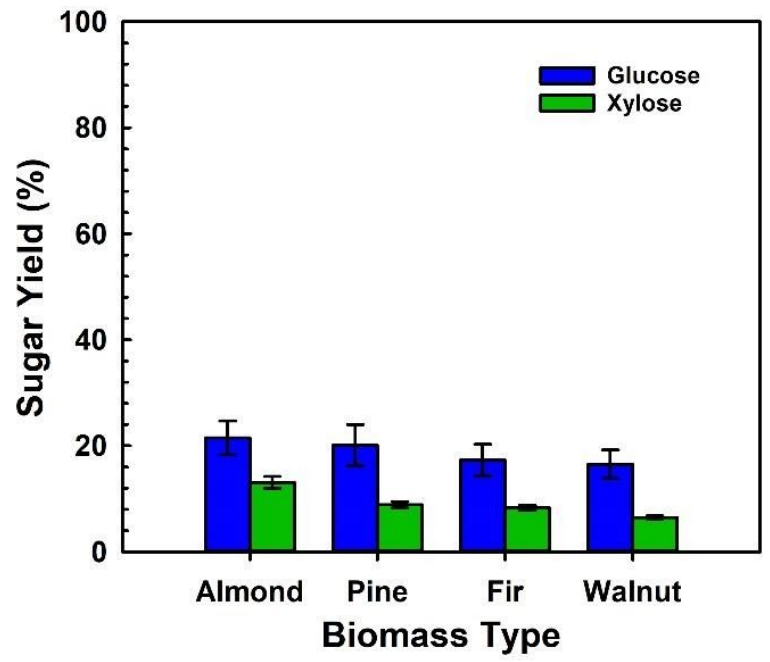

Figure S3. Glucose and xylose yield from enzymatic hydrolysis $(\mathrm{EH})$ of untreated raw biomass using (A) $20 \mathrm{mg}$ protein/g biomass of enzyme; (B) $30 \mathrm{mg}$ protein/g biomass of enzyme, as well as $(\mathrm{C})$ mixed biomass $(\mathrm{MB})$ using $30 \mathrm{mg}$ protein/g biomass of enzyme (weight fraction of Almond/Walnut/Pine/Fir are listed in the figure as A/W/F/P) 
(A)

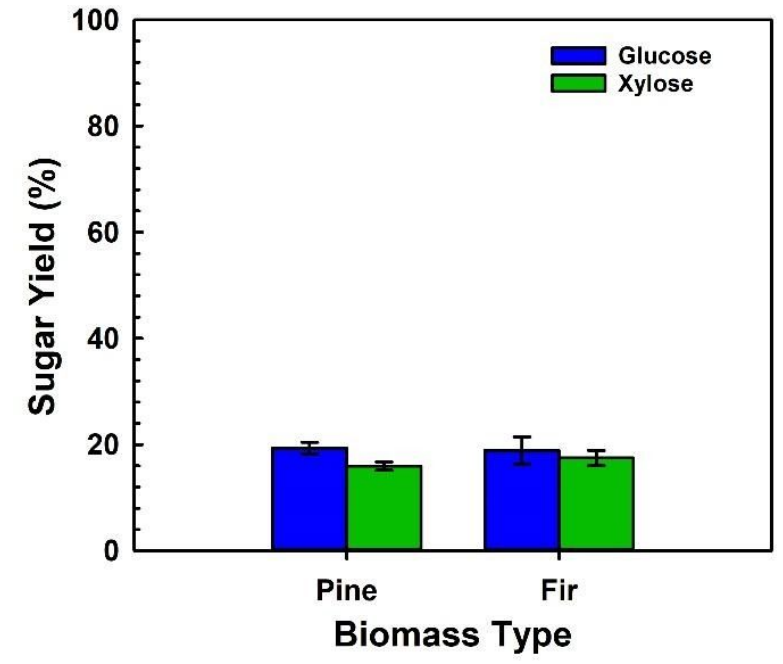

(B)

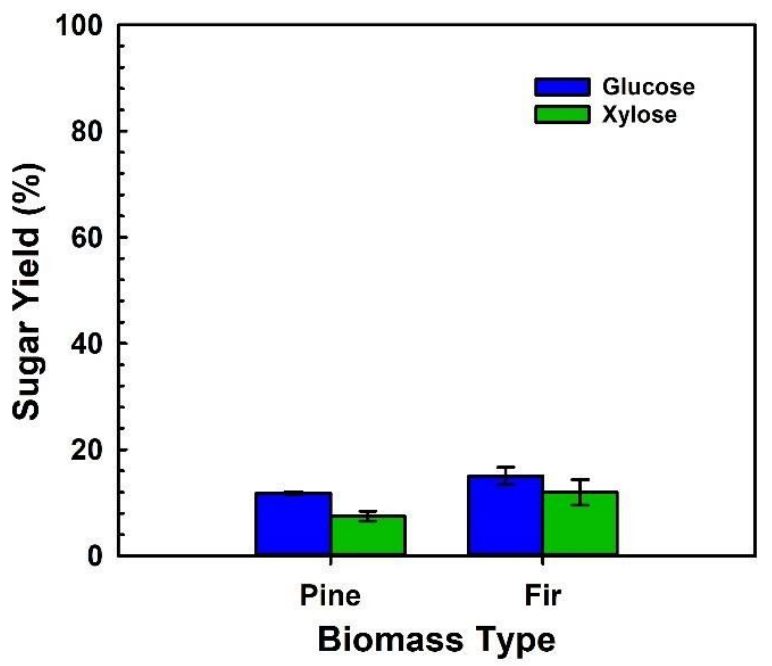

Figure S4. Glucose and xylose yield from enzymatic hydrolysis of $160^{\circ} \mathrm{C}, 6 \mathrm{~h}$, and $30 \mathrm{mg}$ protein $/ \mathrm{g}$ biomass of enzyme for (A) [Ch][Lys]; (B) [EOA][OAc] pretreated samples. 
(A)

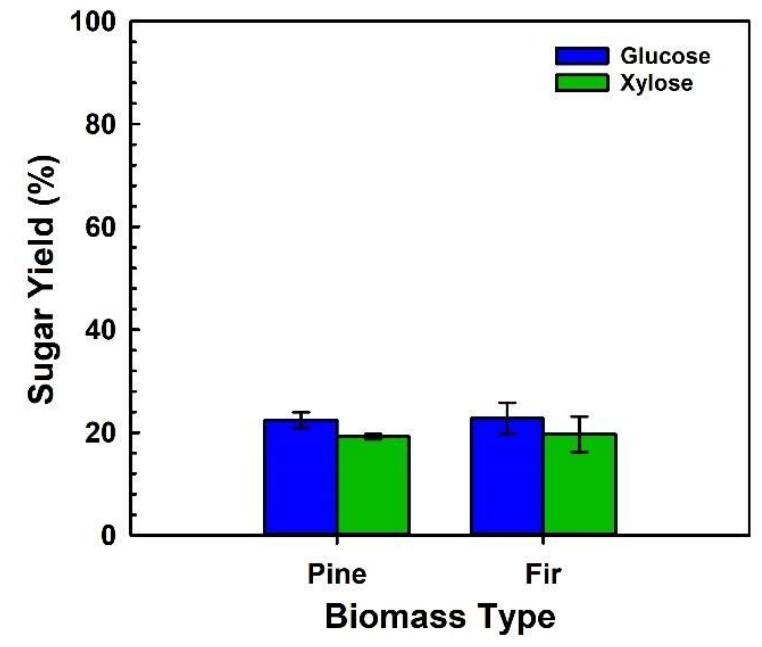

(B)

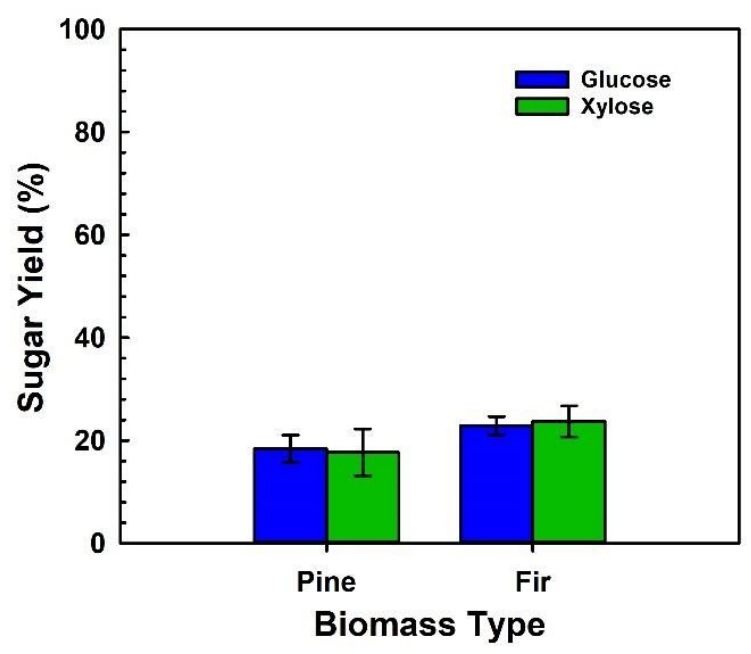

Figure S5. Glucose and xylose yield from enzymatic hydrolysis of $160{ }^{\circ} \mathrm{C}, 3 \mathrm{~h}$, and $27 \mathrm{mg}$ protein $/ \mathrm{g}$ biomass of enzyme with a 7/3 Ctec3/Htec3 enzyme for (A) [Ch][Lys]; (B) [EOA][OAc] pretreated samples. 
(A)

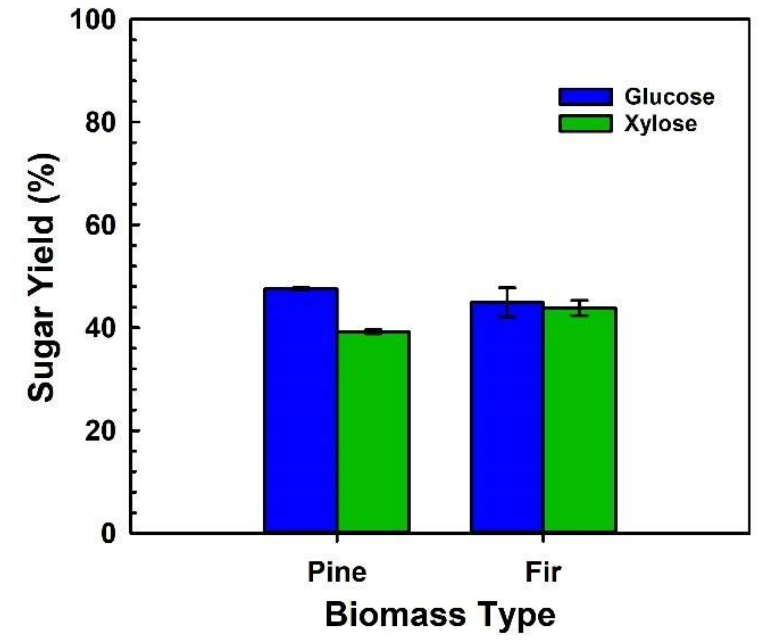

(B)

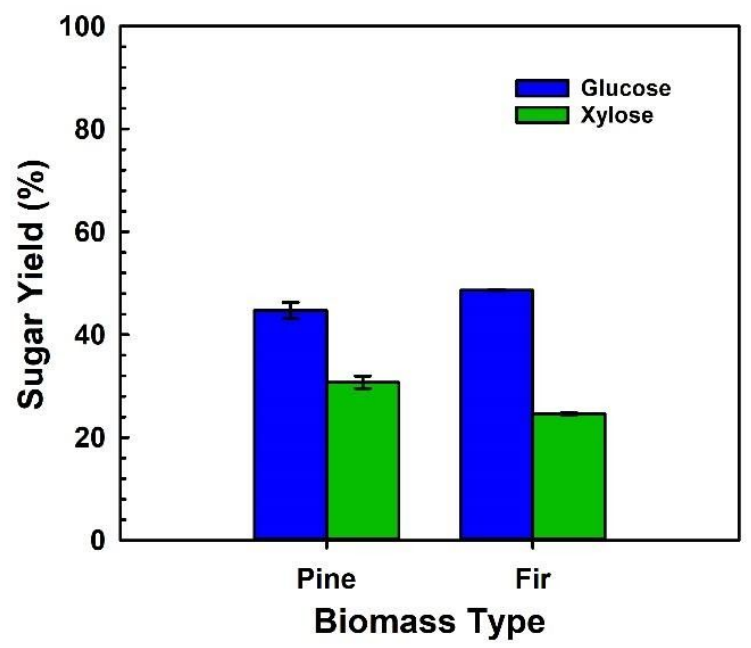

Figure S6. Glucose and xylose yield from enzymatic hydrolysis $50 \mu \mathrm{m}$ particle size of $160{ }^{\circ} \mathrm{C}, 3$ $\mathrm{h}$, and $30 \mathrm{mg}$ protein/g biomass of enzyme for (A) [Ch][Lys]; (B) [EOA][OAc] pretreated samples. 